\title{
Korelasi Peran Modeling Orang tua pada saat Pelaksanaan Perawatan Kesehatan Gigi dengan Dental Fear anak
}

\author{
Dhia Thifal Malihah $^{1 *}$, Inne Suherna Sasmitra ${ }^{1}$, Arlette Suzy Puspa Pertiwi ${ }^{1}$ \\ ${ }^{1}$ Departemen Ilmu Kedokteran Gigi Anak, Fakultas Kedokteran Gigi, Universitas Padjadjaran, \\ Indonesia
}

*Korespondensi:_dhiathifal@gmail.com

\begin{abstract}
ABSTRAK
Introduction: Dental fear merupakan rasa takut terhadap perawatan kesehatan gigi yang sangat terlihat pada anak usia pra sekolah, salah satu pendekatan yang dapat dilakukan adalah metode modeling. Tujuan Penelitian bertujuan untuk mengetahui korelasi antara modeling orang tua pada saat pelaksanaan perawatan kesehatan gigi dengan dental fear anak. Metode: Jenis penelitian merupakan analitik korelatif. Teknik pengambilan sampel adalah purposive sampling. Data dikumpulkan menggunakan kuesioner peran modeling orang tua dan CFSS-DS versi Bahasa Indonesia pada 20 ibu yang memiliki anak berusia tiga hingga enam tahun yang merupakan pasien anak di RSKGM dan pernah dibawa ke dalam ruang praktik selama perawatan kesehatan gigi kepada ibu berlangsung. Analisis data menggunakan uji Spearman Coefficient of Rank Correlation. Hasil: Sebanyak 95\% ibu telah memperlihatkan perilaku positif di hadapan anaknya dan 5\% memperlihatkan perilaku negatif. Dental fear yang dirasakan anak untuk kriteria rendah adalah $40 \%$, sedang $40 \%$, dan tinggi $20 \%$. Hasil analisis pada derajat kekeliruan ${ }^{u}=0,05$ adalah $\mathrm{rs}-0,46$, thitung $-2,19$, p-value 0,020930553, dan penelitian bersifat signifikan dengan keterkaitan antara kedua variabel penelitian 21,05\%. Simpulan: Terdapat korelasi antara modeling orang tua dengan dental fear anak, yaitu semakin ibu memperlihatkan perilaku positif selama mendapatkan perawatan kesehatan gigi, maka semakin rendah dental fear yang dirasakan anak usia tiga hingga enam tahun.
\end{abstract}

Kata Kunci: Korelasi, Peran Modeling Orang Tua, Dental Fear Anak

\section{Correlation of the Role of Modeling Parents when Conducting Dental Health Care with Child's Dental Fear}

\begin{abstract}
Introduction: Dental fear is the fear of dental treatment which is extremely visible in pre-school age children. Modeling method can be used to manage dental fear in children. The objective of this study is to know the correlation between parent's modeling role in dental treatment and children's dental fear age three to six at the Oral and Dental Specialty Hospital in 2018. Methods: The research type is an analytic correlative. The sampling technique used is purposive sampling. Data were collected using parent's modeling method role questionnaire and the Indonesian version of CFSS-DS from 20 mothers of children age three to six which are patients at RSKGM's pediatric clinic and had been brought in to the practice room while their mother received dental treatment. The results are analyzed using Spearman Coefficient of Rank Correlation. Results: The results indicate that 95\% mothers showed positive behavior and 5\% mother showed negative behavior, there are 40\% children with low level of dental fear, $40 \%$ with moderate level of dental fear, and $20 \%$ with high level of dental fear. The analysis results for error degree $\mathrm{u}^{\mathrm{W}}=0,05$ are $r_{s}-0,46$, t-hitung $-2,19, p$-value 0,020930553 , and significant with correlation between two variables is $21,05 \%$. Conclusion: The conclusion of this research is there is a correlation between parent's modeling method role and children's dental fear, which is, the more positive behavior is shown by mothers during dental treatment, the less dental fear children age three to six perceived.
\end{abstract}

Keywords: Correlation, Parent's Modeling Method Role, Children Dental fear 


\section{PENDAHULUAN}

Pasien yang tidak takut terhadap perawatan kesehatan gigi memprediksi rasa sakit sesuai dengan yang telah dibayangkan sebelumnya, sementara pasien yang takut memprediksi rasa sakit secara berlebihan. ${ }^{1}$ Dental fear adalah rasa takut terhadap perawatan kesehatan gigi karena takut terhadap dokter gigi, perawat gigi, suara kebisingan dan getaran dari bor gigi, serta tekanan instrumen tangan selama perawatan berlangsung. ${ }^{2}$ Anak berusia muda merasa takut terhadap perawatan kesehatan gigi dua kali lipat dibanding anak yang berusia lebih tua. ${ }^{3}$ Prevalensi anak yang takut terhadap perawatan kesehatan gigi di Singapura dan Indonesia adalah $14 \%$, dengan anak perempuan merasakan 2,64 kali lebih takut dibandingkan anak laki-laki. ${ }^{4}$

Dental fear biasa ditemukan pada anak dengan usia di bawah tiga hingga sebelas tahun. ${ }^{4}$ Dental fear akan berkurang dengan sendirinya seiring bertambahnya usia, karena kemampuan kognitif anak untuk mengatasi rasa takut juga semakin berkembang. ${ }^{.}$The Children's Fear Survey Schedule Dental Subscale (CFSS-DS) dikembangkan sebagai sebuah instrumen untuk menilai dental fear pada anak. CFSS-DS merupakan perbaikan dari Fear Survey Schedule for Children (FSS-FC). ${ }^{6}$ Usia tiga hingga enam tahun merupakan usia pra sekolah, pada usia tersebut anak sedang mengembangkan rasa takut dari dalam diri sendiri yang dibentuk melalui disiplin orang tua. Anak akan memiliki rasa takut seperti takut jatuh, suara kebisingan, dan berinteraksi dengan orang asing. Rasa takut yang dimiliki pada usia pra sekolah sangat berhubungan dengan suasana pada lingkungan dokter gigi, yaitu adanya suara kebisingan dan getaran alat kedokteran gigi serta keberadaan dokter dan perawat gigi yang dianggap asing.

Faktor-faktor yang dapat memengaruhi perilaku anak selama perawatan kesehatan gigi adalah keluarga, status sosial ekonomi, pengalaman buruk terhadap perawatan kesehatan gigi, dan sikap yang dimiliki orang tua. Salah satu faktor yang memberikan pengaruh besar terhadap dental fear anak usia pra sekolah adalah sikap yang dimiliki oleh orang tua. ${ }^{9} \quad$ ibu memiliki peran yang lebih besar dari ayah dalam pembentukan sikap anak, karena identitas peran keluarga lebih terlihat pada ibu dan ibu memiliki rasa tanggung jawab yang lebih besar dalam hal peningkatan kualitas anak. rasa takut yang dirasakan ibu juga memengaruhi rasa takut ayah dan anak. Perilaku ibu selama mendapatkan perawatan kesehatan gigi dinilai menggunakan kuesioner peran modeling orang tua. ${ }^{9}$

Uraian latar belakang diatas mentoring peneliti melakukan penelitian mengenai korelasi modeling Orang Tua pada saat pelaksanaan perawatan kesehatan gigi dengan dental fear anak dengan target penelitian adalah ibu dari anak yang berusia tiga hingga enam tahun di RSKGM, karena penelitian tersebut belum pernah dilakukan sebelumnya.

\section{METODE}

Jenis penelitian adalah analitik bivariat korelatif, yaitu melihat adanya korelasi antara modeling orang tua pada saat pelaksanaan perawatan kesehatan gigi dengan dental fear anak menggunakan kuesioner peran modeling orang tua dan CFSS-DS versi Bahasa Indonesia. Jumlah sampel yang diambil untuk penelitian adalah 20 ibu dari pasien anak yang berusia tiga hingga enam tahun di Rumah Sakit Khusus Gigi dan Mulut (RSKGM).

Prosedur penelitian adalah dengan menyebarkan kuisioner dengan tahapan sebagai berikut: 1) Peneliti datang ke klinik pedodonsia Rumah Sakit Khusus Gigi dan Mulut; 2) Peneliti memilih sampel yang akan diteliti; 3) Peneliti menjelaskan tujuan dari penelitian kepada ibu yang memenuhi kriteria; 4) Peneliti mengajukan informed consent apabila ibu pasien telah bersedia menjadi subjek penelitian; 5) Ibu pasien menandatangani informed consent yang telah disediakan; 6) Pengisian lembar kuesioner peran modeling orang tua dan kuesioner Children Fear Survey Schedule-Dental Subscale (CFSS-DS) versi Bahasa Indonesia oleh ibu. Hasil disajikan dalam bentuk tabel dan grafik untuk mengetahui korelasi antara peran modeling orang tua pada saat pelaksanaan perawatan kesehatan gigi dengan dental fear anak. Uji statistik yang digunakan adalah uji Spearman Coefficient of Rank Correlation dengan derajat kekeliruan $\propto=0,05$.

\section{HASIL}

Karakteristik responden berdasarkan jenis kelamin dan usia: 
Grafik 1. Children's Dental Fear Berdasarkan Jenis Kelamin

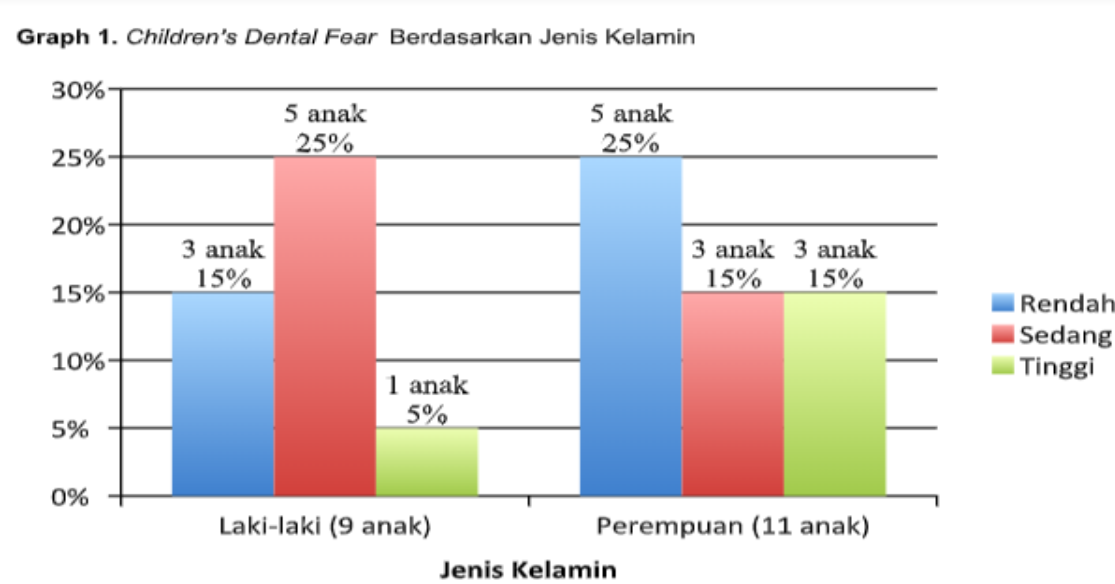

Tabel 1. Children's Dental Fear Berdasarkan Usia

\begin{tabular}{|c|c|c|c|c|c|c|c|c|c|}
\hline \multirow{3}{*}{ Usia Anak (Tahun) } & \multicolumn{9}{|c|}{ Dental Fear } \\
\hline & \multicolumn{2}{|c|}{ Rendah } & \multicolumn{2}{|c|}{ Sedang } & \multicolumn{3}{|c|}{ Tinggi } & \multicolumn{2}{|c|}{ Total } \\
\hline & $\mathbf{F}$ & $\%$ & $\mathbf{F}$ & $\%$ & $\mathbf{F}$ & & $\%$ & $\mathbf{F}$ & $\%$ \\
\hline 3 & 2 & $10 \%$ & 1 & $5 \%$ & 0 & & $0 \%$ & 3 & $15 \%$ \\
\hline 4 & 2 & $10 \%$ & 3 & $15 \%$ & 3 & & $15 \%$ & 8 & $40 \%$ \\
\hline 5 & 2 & $10 \%$ & 2 & $10 \%$ & 0 & & $0 \%$ & 4 & $20 \%$ \\
\hline 6 & 2 & $10 \%$ & 2 & $10 \%$ & 1 & & $5 \%$ & 5 & $25 \%$ \\
\hline \multirow[t]{2}{*}{ Total } & 8 & $40 \%$ & 8 & $40 \%$ & 4 & & $20 \%$ & 20 & $100 \%$ \\
\hline & & & & & lak Meı & dim & Dental Fea & & \\
\hline \multirow[t]{2}{*}{ Ibu Memperlihatkaı } & akı & \multicolumn{2}{|c|}{ Rendah } & \multicolumn{2}{|c|}{ Sedang } & \multicolumn{2}{|c|}{ Tinggi } & \multicolumn{2}{|c|}{ Total } \\
\hline & & $\mathbf{F}$ & $\%$ & $\mathbf{F}$ & $\%$ & $\mathbf{F}$ & $\%$ & $\mathbf{F}$ & $\%$ \\
\hline \multicolumn{2}{|c|}{ Ya } & 8 & $40 \%$ & 8 & $40 \%$ & 3 & $15 \%$ & 19 & $95 \%$ \\
\hline \multicolumn{2}{|c|}{ Tidak } & 0 & $0 \%$ & 0 & $0 \%$ & 1 & $5 \%$ & 1 & $5 \%$ \\
\hline \multicolumn{2}{|c|}{ Total } & 8 & $40 \%$ & 8 & $40 \%$ & 4 & $20 \%$ & 20 & $100 \%$ \\
\hline
\end{tabular}

Tabel 3. Spearman Coefficient of Rank Correlation dari Peran Modeling Orang Tua dan Dental Fear Anak

\begin{tabular}{cccccc}
\hline Var & $r_{s}$ & $t_{\text {hitung }}$ & $p$-value & Sifat & Keterkaitan \\
\hline Ibu dan Anak & $-0,46$ & $-2,19$ & 0,020930553 & Signifikan \\
\hline
\end{tabular}

\section{PEMBAHASAN}

Hasil penelitian menurut grafik 1, terdapat perbedaan tingkat dental fear anak usia pra sekolah terhadap perawatan kesehatan gigi jika ditinjau dari jenis kelamin anak, yaitu, anak perempuan memiliki dental fear kriteria tinggi lebih banyak (15\%) dibanding anak laki-laki (5\%).

Anak perempuan lebih takut terhadap jarum suntik, luka pada tubuh, dan suasana gelap dibanding anak laki-laki. ${ }^{10}$ Berdasarkan penelitian Lin, et al. (2014), dari 316 anak dengan status ekonomi rendah yang terdiri dari 145 anak laki dan 171 anak perempuan,
22 anak laki-laki (6\%) mengalami dental fear kriteria tinggi, dan 56 anak perempuan (17\%) mengalami dental fear kriteria tinggi, sedangkan dari 1154 anak dengan status sosial ekonomi menengah keatas yang terdiri dari 508 anak laki-laki dan 646 anak perempuan, 91 anak laki-laki (7\%) mengalami dental fear kriteria tinggi, dan terdapat 212 anak perempuan (18\%) yang mengalami dental fear kriteria tinggi. ${ }^{11}$ Hal tersebut dikarenakan kurangnya kemampuan anak perempuan untuk menutupi rasa takut yang dirasakan sehingga menyebabkan anak perempuan lebih mampu mengekspresikan rasa takutnya, sedangkan anak laki-laki lebih mampu untuk menyembunyikan dan menutupi rasa takut. ${ }^{12}$ Table 1 Menunjukkan terdapat perbedaan tingkat dental fear 
anak usia pra sekolah terhadap perawatan kesehatan gigi jika ditinjau dari usia anak. Responden usia 4 tahun lebih takut dibandingkan responden usia 5 tahun, dengan persentase dental fear kriteria sedang $15 \%$ untuk 4 tahun dan $10 \%$ untuk 5 tahun, serta dental fear kriteria tinggi $15 \%$ untuk 4 tahun dan $0 \%$ untuk 5 tahun. Penelitian yang dilakukan oleh Oliveira and Colares (2008) mendapatkan hasil anak usia $36-47$ bulan memiliki dental fear sebesar 18,6\% dan usia 48-59 bulan memiliki dental fear sebesar $13,4 \% .^{13}$

Usia merupakan faktor penting dalam dental fear anak. ${ }^{14}$ Anak usia 4 tahun memiliki rasa takut yang paling parah, tetapi rasa takut tersebut akan semakin berkurang seiring bertambahnya usia anak. ${ }^{14}$ dental fear yang dirasakan pada masa anak meningkat saat anak berada pada usia lebih muda dan berkurang seiring dengan bertambahnya usia anak, karena anak yang berusia lebih muda masih memiliki pemahaman yang lebih sedikit dibandingkan yang berusia lebih tua, serta seiring bertambahnya usia, kemampuan anak untuk mengevaluasi situasi juga semakin meningkat. ${ }^{6}$

Secara keseluruhan dari 20 responden, 8 anak (40\%) memiliki dental fear kriteria rendah, 8 anak (40\%) memiliki dental fear kriteria sedang, dan 4 anak (20\%) memiliki dental fear kriteria tinggi. Hasil menunjukkan bahwa, mayoritas responden memiliki dental fear kriteria rendah dan sedang. Berdasarkan penelitian yang telah dilakukan oleh Milgrom, et al. (1992), diperoleh hasil dari 1000 anak, hanya 115 anak (11,5\%) yang mengalami dental fear kriteria tinggi. ${ }^{15}$ Menurut Milgrom, et al. (1995), dental fear kriteria tinggi jarang terjadi pada pasien anak yang memiliki orang tua dengan dental fear kriteria rendah dan sedang. Tabel 3 memperlihatkan 19 ibu $(95 \%)$ yang telah memperlihatkan perilaku positif dan $1 \mathrm{ibu}(5 \%)$ yang memperlihatkan perilaku negatif. Metode modeling merupakan metode pendekatan yang digunakan dalam penelitian. Metode tersebut merupakan metode yang efektif dan dapat dengan mudah dilakukan oleh ibu untuk mengurangi dental fear anak. Metode modeling disebut efektif karena pada masa pra sekolah, anak memiliki rasa ingin tahu yang besar sehingga anak akan mencontoh perilaku yang diperlihatkan oleh ibu dihadapan anak. ${ }^{16}$ Hasil penelitian yang dilakukan sesuai dengan perhitungan statistika pada tabel 4, menunjukkan perhitungan statistika dengan menggunakan uji Spearman Coefficient of Rank Correlation. Perhitungan statistik dapat dilihat pada lampiran. Nilai $\mathrm{r}_{\mathrm{s}}$ yang didapatkan setelah melakukan analisis data menggunakan uji Spearman Coefficient of Rank Correlation dengan derajat kekeliruan ${ }^{\propto}=0,05$ adalah $-0,46 .^{17}$

$\mathrm{t}_{\text {hitung }}$ is $-2,19$ dan $\mathrm{t}_{\text {tabel }}$ is 2,10 , artinya hasil $\mathrm{t}_{\text {hitung }}$ lebih tinggi dibandingkan $\mathrm{t}_{\text {tabel }}$. Artinya $\mathrm{H}_{0}$ ditolak dan $\mathrm{H}_{1}$ diterima. Karena nilai p-value pada penelitian adalah 0,020930553, yang berarti lebih kecil dari derajat kekeliruan yaitu 0,05 , maka hasil analisis penelitian bersifat signifikan pada derajat kekeliruan ${ }^{\propto}=$
0,05, dan persentase dari korelasi peran modeling orang tua pada saat pelaksanaan perawatan kesehatan gigi dengan dental fear anak sebesar 21,05\%. Hasil penelitian memperlihatkan bahwa penelitian memiliki nilai $r_{s}$ negatif. Nilai negatif tidak memengaruhi besar nilai, tetapi hanya untuk menunjukkan hubungan linier, bahwa terdapat hubungan linier negatif sempurna antara variabel $\mathrm{X}$ dan $\mathrm{Y}$, yaitu semakin tinggi nilai variabel $\mathrm{X}$ maka semakin rendah nilai variabel Y, atau sebaliknya. ${ }^{18}$

\section{SIMPULAN}

Terdapat korelasi antara peran modeling orang tua pada saat pelaksanaan perawatan kesehatan gigi dengan dental fear anak, yaitu, semakin ibu memperlihatkan perilaku positif selama mendapatkan perawatan kesehatan gigi di hadapan anak usia pra sekolah, maka semakin rendah dental fear yang dirasakan anak usia pra sekolah.

\section{DAFTAR PUSTAKA}

1. Arntz A, Heumans M. Predictions of dental pain: the fear of any expected evil, is worse than the evil itself. PubMed. 1990;28(1): pp. 29-41.

2. Pinkham, J.; P. Casamassimo; D. McTigue; Fields, H. 2005. Pediatric Dentistry: InfacyThrough Adolescence. 4th ed. Philadelphia: Elsevier Inc.

3. Raadal M, Milgrom P. Weinstein P. Mancl L. The prevalence of dental anxiety in children from low-income families and its relationship to personality traits. Journal of Dental Research. 1995;74(8): pp. 1439-43.

4. Maria, A.R.; V. Feraru; C. Herteliu; R. Anghelescu. Assessment of the prevalence of dental fear and its causes among children and adolescents attending a department of paediatric dentistry in Bucharest. 2009;8(1): pp. 42-49.

5. Youn-Soo, S. 2015. Dental fear and anxiety and dental pain in children and adolescents: a systemic review. Journal of Dental Anesthesia and Pain Medicine. 15(2): pp. 53-61.

6. Berge MT, Veerkamp JSJ. Hoogstraten PJM, Prins. On the structure of childhood dental fear, using the Dental Subscale of the Children's Fear Survey Schedule. European Journal of Pediatric Dentistry. 2002;3(2):73-80.

7. Finn, S. Clinical Pedodontics. 4th ed. Philadelphia: W.B.Saunders. 2003 
8. Lara, A, Crego MR, Maroto. Emotional contagion of dental fear to children: the father\&\#39;s mediating role in parental transfer of fear. International Journal of PediatricDentistry. 2011;22:324-30.

9. Barnett, R.C.; R.T. Brennan; N.L. Marshall. Gender and the relationship between parent role quality and psychological distress. J Fam. 1994;15(2):229-52.

10. Burnham JJ, Lomax RG. Examining race/ethnicity and fears of children and adolescents in the United States: differences between white, african american, and his panic populations. Journal of Counseling and Development. 2009;87(4): pp. 387-93.

11. Lin YL, Yen YY, Chen HS. Child dental fear in lowincome and non-low-income families: A schoolbased survey study. Journal of Dental Sciences. 2014;9(2): 165-71.

12. Liddell, A.; M. Rabinowitz; C. Peterson. Relationship Between Age Changes in Children\&\#39; Dental Anxiety and Perception of
Dental Experiences. Canada: Plenum Publishing Corporation. 1994.

13. Oliveir MM, Colares V. The relationship between dental anxiety and dental pain in children aged 18 to 59 months: a study in Recife, Pernambuco State, Brazil.2008

14. Koch GS, Poulsen. Pediatric Dentistry - A Clinical Approach. $2^{\text {nd }}$ ed. UK: Wiley-Block Well. 2009.

15. Milgrom P, Vignehsa HP. Weinstein. Adolescent dental fear and control. 1992

16. Prevalence and theoretical implications. Behaviour Research and Therapy. 1992;30(4):367-73.

17. Catherine L. Practice development: training professionals in primary care to manage emotional and behavioural problems in children. Work Based Learning in Primary Care. 2004;2(1): 97-101.

18. Sugiono. Metode Penelitian Kualitatif, Kuantitatif, dan RandD. Bandung: Alfabeta.2011

19. Riwidikdo, H. Statistik Kesehatan. Yogyakarta: Mitra Cendekia. 2010 